Accepted refereed manuscript of: Gavriilidis K, Kambouroudis DS, Tsakou K \& Tsouknidis DA (2018) Volatility forecasting across tanker freight rates: the role of oil price shocks. Transportation Research Part E: Logistics and

Transportation Review, 118, pp. 376-391. DOI: 10.1016/j.tre.2018.08.012

(C) 2018, Elsevier. Licensed under the Creative Commons AttributionNonCommercial-NoDerivatives 4.0 International

http://creativecommons.org/licenses/by-nc-nd/4.0/ 


\title{
Volatility forecasting across tanker freight rates: the role of oil price shocks*
}

\author{
Konstantinos Gavriilidis ${ }^{\dagger} \quad$ Dimos S. Kambouroudis ${ }^{\ddagger}$ \\ University of Stirling \\ University of Stirling \\ Katerina Tsakou ${ }^{\S}$ \\ Dimitris A. Tsouknidis \\ Swansea University Cyprus University of Technology
}

\begin{abstract}
This paper examines whether the inclusion of oil price shocks of different origin as exogenous variables in a wide set of GARCH-X models improves the accuracy of their volatility forecasts for spot and 1-year time-charter tanker freight rates. Kilian's (2009) oil price shocks of different origin enter GARCH-X models which, among other stylized facts of the tanker freight rates examined, take into account the presence of asymmetric and long-memory effects. The results reveal that the inclusion of aggregate oil demand and oil-specific (precautionary) demand shocks improves significantly the accuracy of the volatility forecasts drawn.
\end{abstract}

Keywords: volatility forecasts; tanker freight rates; oil price shocks; GARCH-X models. JEL classification: G11, G12, G13, G14, G20, G24.

\footnotetext{
*The authors would like to thank David McMillan for his helpful comments.

†University of Stirling Management School, Stirling, FK9 4LA, UK. Tel: +44 (0) 1786 467298, Email: konstantinos.gavriilidis@stir.ac.uk.

${ }^{\ddagger}$ University of Stirling Management School, Stirling, FK9 4LA, UK. Tel: +44 (0) 1786 467296, Email: d.s.kambourpoudis@stir.ac.uk.

${ }^{\S}$ Swansea University, School of Management, Swansea, SA1 8EN, UK. Tel: +44 (0) 1792513238 , Email: katerina.tsakou@swansea.ac.uk.

IDepartment of Commerce, Finance and Shipping, 115 Spyrou Araouzou Street, P.O. Box 50329, Limassol, Cyprus. Tel: +357 2500 2058, Email: dimitris.tsouknidis@cut.ac.cy.
} 


\section{Introduction}

Seaborne transportation is the leading form of transporting goods worldwide, carrying more than $80 \%$ of global trade in terms of volume (UNCTAD, 2017). Out of all seaborne transported commodities, oil and oil products are among the most important in terms of trading value according to a 2016 report by Clarksons, which states that the value of oil transported through sea during the year 2015 was approximately equal to $\$ 717 \mathrm{bn} .{ }^{1,2}$ Tanker freight rates, being the cost of transportation through sea for oil and oil products, have been shown to exhibit pronounced volatilities over time (Kavussanos, 1996a; Drobetz, Richter, and Wambach, 2012; Tsouknidis, 2016). ${ }^{3}$ The demand for tanker ships is largely a derived demand for their cargo of oil, which in turn is determined by the international seaborne trade in oil and oil products (Stopford, 2009). In this way, oil price stylized characteristics, such as the excess volatility and cyclicality are expected to be reflected to some extent into tanker freight rates. Thus, given the dependence of the global economy on crude oil and oil products and the pronounced fluctuations of oil price reflected in tanker freight rates, forecasting tanker freight volatility is of paramount importance to several participants in the oil and shipping markets, such as oil producers, traders, refineries, distributors as well as tanker owners and banks financing such investments. ${ }^{4}$

Several studies have been devoted on modeling and forecasting volatility in tanker freight markets (Chen and Wang, 2004; Adland and Cullinane, 2006; Alizadeh and Nomikos,

\footnotetext{
${ }^{1}$ https://clarksonsresearch.wordpress.com/2016/07/22/just-how-big-is-an-economy-without-borders/.

${ }^{2}$ According to the statistical review of world energy (British Petroleum, 2015), world's dependence on energy commodities remains large as the percentages of global energy consumption among all sources of energy is the following: crude oil and oil products (32.6\%), coal (30\%), natural gas (23.7\%), hydroelectric energy $(6.8 \%)$, nuclear energy $(4.4 \%)$ and renewables $(2.5 \%)$. The importance of petroleum-based commodities for the global economy and economic development has been highlighted as early as in Hamilton (1983). Furthermore, oil price shocks have been shown to affect the U.S. stock market (Kilian and Park, 2009).

${ }^{3}$ For an overview on shipping finance, see Alexandridis, Kavussanos, Kim, Tsouknidis, and Visvikis (2018); and for ways to manage risks in the shipping freight rate market using shipping derivatives, see Kavussanos and Visvikis (2006). Shipping derivatives have been shown to: lead their corresponding spot markets (Kavussanos and Visvikis, 2004); exhibit economic spillovers among shipping sub-segments (Kavussanos, Visvikis, and Dimitrakopoulos, 2014; Alexandridis, Sahoo, and Visvikis, 2017) and carry liquidity premia (Alizadeh, Kappou, Tsouknidis, and Visvikis, 2015).

${ }^{4}$ The frequent episodes of extreme volatility in oil prices can be documented by data from the U.S. Department of Energy, where oil prices tumbled from $106.2 \$$ /barrel in June 2014 to $26.55 \$$ /barrel in January 2016.
} 
2011; Drobetz et al., 2012), while related literature has included oil price as an exogenous variable in a GARCH-X setting (Kavussanos, 1996a; Drobetz et al., 2012). This literature developed primarily as a response to the importance of the tanker freight market for the transportation of the world's main energy source being oil and oil products and the unique stylized facts of tanker freight rates which are inherited to some extent from the stylized facts of oil price. Specifically, early research by Kavussanos (1996a,b) estimates a set of GARCH models to establish that i) freight rates and second-hand vessel prices are timevarying, ii) the volatility of larger vessel's prices is higher than the one of smaller vessels and iii) using oil price as an exogenous variable significantly improves forecasts of tanker volatility. In another study, Chen and Wang (2004) document an asymmetric (larger) effect in freight rates' volatility in response to negative changes in freight rates when compared to positive ones. Alizadeh and Nomikos (2011) reveal that freight rate volatility is related to the term structure of the freight market and this relationship is asymmetric, as volatility is higher when the freight market is in backwardation and lower when in contango. ${ }^{5}$ Drobetz et al. (2012) examine the dynamics of time-varying volatility in both dry bulk and tanker freight markets, using a GARCH model with exogenous variables (GARCH-X) and an EGARCH model. The authors show that macroeconomic factors provide additional explanatory power when included in the conditional variance equation of these models. The authors document the lack of asymmetry effects in the dry bulk freight market, but their pronounced presence in the tanker freight market. Overall, the results of Kavussanos (1996a) and Drobetz et al. (2012) suggest that the inclusion of oil, as well as other macroeconomic variables (i.e. GDP growth, stock market return, interest rate yields), can improve the forecasting power of volatility models. In a related study, Tsouknidis (2016) provides evidence of large time-varying volatility spillovers within and between the dry bulk and tanker sub-segments; which are far larger during and after the period of the global financial crisis. ${ }^{6}$

\footnotetext{
${ }^{5}$ Backwardation is the state of the market when the futures price is below the expected future spot price, i.e. in favor of traders being "net long" in their positions. Contango refers to the opposite case.

${ }^{6}$ Another strand of the literature aims on forecasting spot and forward prices of freight markets. For example, Cullinane (1992) and Cullinane, Mason, and Cape (1992) provide evidence on the ability of univariate ARIMA models to forecast spot freight rates. Kavussanos and Nomikos (2003) report that vector equilibrium correction models (VECM) produce accurate forecasts for spot freight prices but not for futures freight prices. Batchelor, Alizadeh, and Visvikis (2007) find that i) VECM models produce the best in-sample fit, ii) forward rates can be helpful on forecasting future spot rates, and iii) ARIMA and VAR models perform better than VECM models on forecasting forward rates. Furthermore, trading
} 
Shi, Yang, and Li (2013) investigate the relationship between tanker freight rates and oil price shocks of different origin as introduced by Kilian (2009), who is the first to reveal that the origin of an oil-price shock determines its effect on the global economy and the stock market (Kilian and Park, 2009). ${ }^{7}$ Specifically, the authors adopt and extend Kilian's framework by investigating the effect of different oil price shocks on the Baltic Dirty Tankers Index (BDTI). The authors show that crude oil supply shocks have significant effects on the BDTI index, whereas the impact of crude oil demand shocks are not as significant. Overall, their results reveal that the effects of oil price shocks on tanker freight rates are weak. In related studies, Chen, Miao, Tian, Ding, and Li (2017) and Zhou (2012) examine the crosscorrelations between the West Texas International crude oil (WTI) and Baltic Exchange Dirty Tanker Index (BDTI) by employing the Multifractal Detrended Cross-Correlation Analysis (MF-DCCA). The authors show that the degree of short-term cross-correlation is higher than that in the long term and that the strength of multifractality after financial crisis is larger than that before. However, using an aggregate tanker freight rates index, such as the BDTI, misses differences (fixed effects) arising from different freight contracts, i.e. spot vs. time-charter rates, and of vessel sizes in the tanker segment, i.e. VLCC, Suexmax, Aframax, Medium Range Product Tankers (MR), examined.

Despite the plethora of studies on modeling and forecasting volatility of tanker freight rates, the extant literature misses completely the growing empirical evidence supporting that the origin of oil price shock determines its effect to the global economy, the financial markets and the shipping sector (Kilian, 2009; Kilian and Park, 2009; Lambertides et al., 2017; Shi et al., 2013). Filling this gap in the literature, this paper is the first to investigate if oil price shocks of different origin can improve volatility forecasts drawn from a wide set of popular GARCH models for tanker freight rates across freight contracts (spot and 1-year time charter contracts) and vessel sizes (VLCC, Suezmax, Aframax, MR).

Regarding the effects of oil price shocks of different origin to oil price and the global economy, Kilian (2009) provides empirical evidence that crude oil production disruptions cause a small and transitory increase in the real price of oil within the first year. In turn, an increase in aggregate demand for all industrial commodities causes a somewhat delayed,

and liquidity characteristics, such as the volume of trading and open interest have been shown to improve forecasts for freight forward agreements (FFA's) (Alizadeh, 2013) and oil futures contracts (Magkonis and Tsouknidis, 2017).

${ }^{7}$ The oil price shocks have been shown to affect stock returns mainly through shocks on stock order flow imbalances (Lambertides, Savva, and Tsouknidis, 2017). 
but sustained, increase in the real price of oil that is also substantial. Finally, an increase in precautionary demand for crude oil causes an immediate, persistent, and large increase in the real price of crude oil. Furthermore, decompositions of fluctuations in the real price of oil show that oil price shocks historically have been driven mainly by a combination of global aggregate demand shocks and precautionary demand shocks, rather than oil supply shocks, as it is commonly believed.

Extending the above rationale, we expect that different oil price shocks may affect differently the volatility forecasting power of GARCH-X models for tanker freight rates. For example, an increase in oil price due to an unexpected crude oil supply disruption may cause an immediate decrease in the demand in the shipping market for transportation of oil. By contrast, an oil price increase due to an unexpected increase in the global real economic activity may cause a boost in the demand in the shipping market for transportation of oil as the world's production increases and more energy resources are needed.

Another channel through which crude oil price shocks may affect tanker freight rates is through changing the level of transportation costs. Specifically, tanker vessels consume the so-called bunkers (fuel oil) whose price is highly correlated with crude oil prices. ${ }^{8}$ An unexpected increase in crude oil price inevitably increases costs and deteriorates profitability - ceteris paribus - of the shipowners and the charterers under a spot and time-charter agreement, respectively. However, if the oil price increase is not due to a crude oil supply disruption but due to a real economic activity increase, shipowners may be able to earn a higher freight rate to compensate the increased fuel costs of their vessels. In order to reveal which of the above economic mechanisms are supported by empirical evidence, this paper examines whether oil price shocks of different origin can improve volatility forecasts of tanker freight rates across charter contracts and vessel sizes.

This study contributes to the extant literature in two ways: first, it provides empirical evidence revealing that oil price shocks carry significant information that improves the accuracy of volatility forecasts for tanker freight rates. This is achieved by including oil price shocks of different origin as exogenous variables into a wide set of popular GARCH-X models. Second, it employs a number of different GARCH models, including the second and third generation GARCH models, which are able to take into account the presence of asymmetric and long-memory effects in the tanker freight rates examined. These features of tanker freight rates have been largely neglected in the extant literature. The findings of this

\footnotetext{
${ }^{8}$ Bunker fuel costs are considered a voyage cost and for this reason are paid by the shipowner in the case of a spot charter agreement and by the charterer in the case of a time-charter agreement.
} 
paper bear important implications for shipping companies, oil importers and banks in their effort to quantify and hedge their risks when operating within the shipping industry. This is mainly because several of the examined tanker freight rates serve as the underlying assets for settling shipping freight derivatives contracts, such as the Forward Freight Agreements (FFA's) and freight options. As such, the forecasting exercise performed in this paper for tanker freight rates is of paramount importance for the participants in the shipping derivatives market amongst others.

The results of this paper suggest that the inclusion of aggregate oil demand and precautionary oil-specific demand shocks (price) as exogenous variables in GARCH-X models significantly improves their forecast ability in statistical terms. Specifically, the inclusion of precautionary oil-specific demand shocks leads to slightly better overall volatility forecasts when compared to aggregate oil demand shock. In contrast, the inclusion of oil supply shocks yields only modest improvements of the volatility forecasts drawn across tankers vessel sizes and freight contracts. In addition, the volatility forecasts are overall more accurate for the 1-year time-charter tanker freight rates which are known to be less volatile rather than their spot market equivalents.

The rest of the paper is organized as follows: Section 2 outlines the methodology; Section 3 describes the data; Section 4 presents the results; Section 5 discusses the results against the existing literature; whereas Section 6 concludes the paper.

\section{Methodology}

\subsection{Disentangling oil price shocks}

We follow Kilian's (2009) structural VAR model in order to distinguish three oil price shocks: oil supply shock, aggregate demand shock and precautionary oil-specific demand shock. Specifically, the estimated SVAR model incorporates monthly data for the vector time series $y$, consisting of the percent change in global crude oil production, the measure of real activity in global industrial commodity markets and the real price of crude oil. The structural representation of the VAR model of order $\mathrm{p}$ is:

$$
A_{0} y_{t}=c_{0}+\sum_{i=1}^{p} A_{i} y_{t-i}+\varepsilon_{t}
$$

where $y_{t}=\left(\Delta \operatorname{prod}_{t}, r e a_{t}, r p o_{t}\right)$, is a $3 \times 1$ vector of endogenous variables, $A_{0}$ refers to the $3 \times 3$ contemporaneous coefficient matrix, $c_{0}$ represents a $3 \times 1$ vector of constant returns, 
$A_{i}$ denotes the $3 \times 3$ autoregressive coefficient matrices and $\varepsilon_{t}$ stands for the $3 \times 1$ vector of structural disturbances, assumed to have zero covariance and being serially uncorrelated. $\Delta \operatorname{prod}_{t}$ is the percentage change in world oil production, $r e a_{t}$ is the global real economic activity for all industrial commodities ${ }^{9}$ rpo $_{t}$ are the real prices of oil.

A long lag length of 24 months $(\mathrm{p}=24)$ is used to allow for potential delays between structural oil demand and oil supply shocks and their effect on the economy. In addition, such a long number of lags removes serial correlation effects. Previous literature on the issue, see for e.g. Kilian and Lutkepohl (2017), has shown that introducing long lags is important in structural models of the global oil market as they take into account the low frequency co-movement between the real price of oil and the global economic activity. In order to arrive to the reduced form VAR model we multiply both sides of Eq. (1) with $A_{0}^{-1}$ which follows a recursive structure for the reduced form errors $e_{t}$ to be linear combinations of the structural errors $\varepsilon_{t}$ as follows:

$$
e_{t}=\left[\begin{array}{c}
e_{1 t}^{\Delta} \text { global oil production } \\
e_{2 t}^{\text {global real activity }} \\
e_{3 t}^{\text {real price of oil }}
\end{array}\right]=\left[\begin{array}{ccc}
\alpha_{11} & 0 & 0 \\
\alpha_{21} & \alpha_{22} & 0 \\
\alpha_{31} & \alpha_{32} & \alpha_{33}
\end{array}\right]\left[\begin{array}{c}
\varepsilon_{1 t}^{\text {oil supply shock }} \\
\varepsilon_{2 t}^{\text {aggregate demand shock }} \\
\varepsilon_{3 t}^{\text {oil specific-demand shock }}
\end{array}\right]
$$

where, $\varepsilon_{1 t}^{\text {oil supply shock }}$ stands for the oil supply side shock, $\varepsilon_{2 t}^{\text {aggregate demand shock }}$ denotes the aggregate demand shock, $\varepsilon_{3 t}^{\text {oil specific-demand shock }}$ captures the oil market-specific demand shock. The economic rationale for the identifying restrictions imposed in $A_{0}^{-1}$ is explained in detail in Kilian (2009). The reduced-form VAR model is estimated by the least squares method. The model is estimated recursively over the out-of-sample period. Subsequently, the estimates are used to construct the structural representation of the VAR model. We follow Goncalves and Kilian (2004) and make inferences on a recursive-design wild bootstrap with 2,000 replications.

\subsection{GARCH modeling for tanker freight rates}

Since its inception by Engle (1982), the ARCH methodology flourished within the literature on volatility forecasting. This is evident by the plethora of models introduced to

\footnotetext{
${ }^{9}$ The global real economic activity refers to equally weighted growth rates of freight rates for individual voyages of bulk dry cargoes. These freight rates are deflated using the US consumer price index and linearly de-trended to remove long-term trends in demand for sea transport and the effects of technological advances in ship building (Kilian, 2009).
} 
address the stylized facts of financial time series, such as clustering, asymmetry and long memory. Such characteristics are taken into consideration when selecting the GARCH models employed to forecast tanker freight rates. Specifically, we employ the GARCH model by Engle (1982) and Bollerslev (1986); the second-generation asymmetric models, namely the EGARCH model of Nelson (1991), the threshold-GARCH (TGARCH) model by Glosten, Jagannathan, and Runkle (1993), also known as the GJR-GARCH model, and the Asymmetric Power-ARCH (APARCH) model by Ding, Engle, and Granger (1993). Importantly, we employ two third-generation long-memory models, namely the IntegratedGARCH (IGARCH) model of Engle and Bollerslev (1986) and the Component-GARCH (CGARCH) model of Engle and Lee (1999). A brief description of the models estimated is provided below. ${ }^{10}$

The GARCH(1,1) model of Engle (1982) and Bollerslev (1986) is expressed as:

$$
h_{t+1}^{2}=\omega+\alpha \varepsilon_{t}^{2}+\beta h_{t}^{2}
$$

where $h_{t}^{2}$ is the conditional volatility and $\varepsilon_{t}^{2}$ is the volatility news.

The EGARCH model of Nelson (1991) is expressed as:

$$
\log \left(h_{t+1}^{2}\right)=\omega+\alpha\left|\frac{\varepsilon_{t}}{h_{t}}\right|+\gamma \frac{\varepsilon_{t}}{h_{t}}+\beta \log \left(h_{t}^{2}\right)
$$

The TGARCH model of Glosten et al. (1993) is given by:

$$
h_{t+1}^{2}=\omega+\alpha \varepsilon_{t}^{2}+\gamma \varepsilon_{t}^{2} I_{t}+\beta h_{t}^{2}
$$

where $I_{t}$ is an indicator variable that equals to one if the error term $\varepsilon_{t}$ is negative and zero otherwise. Asymmetry arises when the $\gamma$ term is statistically significant.

The APARCH by Ding et al. (1993) is given by:

$$
h_{t}^{\delta}=\omega+\alpha_{1}\left(\left|\varepsilon_{t}-1\right|-\gamma \varepsilon_{t-1}\right)^{\delta}+\beta_{1} h_{t-1}^{\delta}
$$

The mathematical expression of the IGARCH model is similar to that of a GARCH model (1) where $\alpha+\beta$ should be equal to 1 , in order for the conditional variance to be nonstationary.

Finally, the CGARCH model by Engle and Lee (1999) is expressed as:

$$
h_{t+1}^{2}=q_{t+1}+\alpha\left(\varepsilon_{t}^{2}-q_{t}\right)+\beta\left(h_{t}^{2}-q_{t}\right)
$$

\footnotetext{
${ }^{10}$ For a detailed literature review on GARCH models, please see Poon and Granger (2003).
} 
where $q_{t}$ represents long-run volatility. Finally, the error term $\varepsilon_{t}$ follows a t-distribution in order to better capture the fat tails of empirical distributions of the freight rates series examined (Drobetz et al., 2012). We augment the GARCH-X models by including as exogenous variables the structural shocks identified in the SVAR model. In this way, we assess whether oil price shocks of different origin contain relevant information when drawing volatility forecasts for the tanker freight rates.

\subsection{Assessing the accuracy of volatility forecasts}

Both the SVAR model and the GARCH-X specifications are estimated recursively over the out-of-sample period by increasing the sample length by one observation. In other words, the initial estimation date is fixed and, once a forecast is obtained, the end in-sample date is expanded by one observation to incorporate the most recent information and the models are re-estimated.

In order to assess the accuracy of the volatility forecasts drawn, two statistical loss functions are used, namely the Mean Absolute Error (MAE) and the Mean Squared Error (MSE). We define the true volatility $\left(\sigma_{t}^{2}\right)$ by following the procedure described in Pagan and Schwert (1990), where true volatility is proxied by the squared error from the conditional mean model of the returns estimated over the whole dataset. According to Andersen and Bollerslev (1998) and Patton (2011), squared returns provide an unbiased estimate of true volatility. ${ }^{11}$ The mathematical expressions for the statistical loss functions are given by:

$$
\begin{aligned}
& M A E=\frac{1}{J} \sum_{t=1}^{J}\left|\sigma_{t}^{2}-h_{t}^{2}\right| \\
& M S E=\frac{1}{J} \sum_{t=1}^{J}\left(\sigma_{t}^{2}-h_{t}^{2}\right)^{2}
\end{aligned}
$$

\footnotetext{
${ }^{11}$ If true volatility $\left(\sigma_{t}^{2}\right)$ is correctly specified, then $E_{t-1}\left(r_{t}^{2}\right)=E_{t-1}\left(\sigma_{t}^{2} \cdot z_{t}^{2}\right)=\sigma_{t}^{2}$; this justifies the use of squared returns as a proxy for ex-post volatility over the relevant horizon. Although the square returns provide an unbiased estimate for the latent volatility factor, it may yield very noisy measurements due to the idiosyncratic error term $z_{t}^{2}$ (Andersen and Bollerslev, 1998). According to Patton (2011), several standard methods for forecast evaluation and comparison, such as the Mincer and Zarnowitz (1969), regression, the West (1996) test and the Diebold and Mariano (1995) (employed in this study), can be applicable when such a conditionally unbiased proxy is used.
} 
where $J$ is the number of out-of-sample observations, $h_{t}$ refers to the out-of-sample forecasts and $\sigma_{t}^{2}$ denotes the true volatility. The smaller the value for each statistic, the closer the forecast is to the true volatility and thus the more accurate the forecast. Subsequently, we assess the forecasting power of the estimated GARCH models by computing the MAE and MSE statistics. Both statistics account for offsetting forecast errors. However, the MAE statistic does so in a proportionate way, while the MSE penalizes large forecast errors. Furthermore, in order to test the statistical significance of the forecasts drawn we rely on the Diebold and Mariano (1995) (DM) test. Specifically, the DM test evaluates the forecast performance of two competing models with the null hypothesis being that of equal predictive accuracy between the benchmark model and the competing model under the MAE and MSE metrics as defined in Eqs. (8) and (9).

\section{Data description}

The data examined in this study comprise average long-run historical earnings for the spot (voyage) and 1-year time-charter markets across vessel sizes for the dry-bulk (Capesize, Panamax and Handysize) and tanker (VLCC, Suezmax, Aframax and MR) segments. These earnings are calculated and published by Clarksons Shipping Intelligence Network (SIN) and represent the daily earnings of a specific vessel under a voyage charter of employment, i.e. earnings are estimated from voyage freight rates, and expressed in \$/day for the voyage, for details please refer to Clarksons (2013) documentation, titled: Sources \& Methods for the Shipping Intelligence Weekly. All data are from Clarksons Shipping Intelligence Network (SIN) and span the period January 1990 to December 2016, which incorporates more than one shipping cycles, i.e. more than 6-7 years according to Stopford (2009). We adopt a recursive framework and obtain one-step-ahead forecast for the period January 2004 and December 2016. ${ }^{12}$ In order to ensure the stationarity of the time series we calculate their first logarithmic differences as dictated by the augmented Dickey and Fuller (1981) (ADF) an Phillips and Perron (1988) (PP) stationarity tests. 13 By using tanker freight rates across different freight contracts and vessel sizes we take into account

\footnotetext{
${ }^{12}$ The sample from January 1990 to December 2003 is used to generate the forecast for January 2004. The prediction for February 2004 is obtained using the estimation period from January 1990 to January 2004, and so on.

${ }^{13}$ We perform the $\mathrm{ADF}$ and $\mathrm{PP}$ tests on the freight rates times series under the recursive estimation setting, i.e. the sample is increased by one month each time.
} 
the different duration of ship voyages in the spot and the time-charter markets and the different dynamics of the markets for tanker vessels of different sizes.

In addition to the data above, monthly observations are utilized for world oil production, a measure of global economic activity and oil prices as the U.S. refiner's acquisition cost of imported crude oil. Both world oil production and oil prices are from the US Department of Energy. The percentage change in world oil production is measured by $100 \mathrm{x}$ log difference in the world oil production in millions of barrels pumped per day averaged by month. The real price of oil is the nominal price of oil deflated by the U.S. consumer price index (CPI) from the Bureau of Labor Statistics. All prices are expressed in dollars and transformed in log-returns. Global real economic activity is measured by the index constructed by Kilian (2009). ${ }^{14}$ This index has the advantage that it incorporates activity in important emerging economies such as China and India, which are not included in conventional measures of global economic activity for OECD countries.

Table 1 presents the descriptive statistics of the logarithmic first differences of the time series examined. As shown, the mean values appear positive for all time series except the spot rates of Aframax vessels. Based on the standard deviations reported and in line with the literature (Kavussanos, 1996b; Tsouknidis, 2016), spot rates appear much more volatile than their time-charter equivalents for all vessel sizes. Finally, the p-values of the Jarque-Bera test indicate that the null hypothesis of normality is strongly rejected in all cases.

\section{[INSERT TABLE 1 HERE]}

\section{Empirical Results}

As discussed earlier, this paper employs a wide set of popular GARCH-type models to explore whether the inclusion of oil price shocks of different origin improves the volatility forecasts for the spot and 1-year time charter contracts and across tanker vessels sizes. Table 2 reports the MAE and MSE values when drawing volatility forecasts without including any exogenous variable in the variance equation of the GARCH models estimated (benchmark). These benchmark values of the MAE and MSE statistics are compared to the ones obtained from the estimation of the GARCH-X models, i.e. when exogenous variables are included in the GARCH models. As observed in Table 2, the long memory IGARCH

\footnotetext{
${ }^{14}$ The data are available at Kilian's webpage: http://www-personal.umich.edu/lkilian/paperlinks.html.
} 
and CGARCH models produce overall the most accurate volatility forecasts across the spot and 1-year time-charter rates; with the only exception being the Spot Medium Range tanker freight rate where the APARCH model exhibits the smallest MAE and MSE values. Specifically, the IGARCH model returns the most accurate volatility forecasts as it minimizes the MAE and MSE values in the majority of the cases examined. Finally, the MSE statistic exhibits overall smaller values for time-charter rates rather than for spot rates across different GARCH specifications. This can be attributed to the fact that the time-charter rates are typically less volatile than their equivalent spot freight rates. The smaller volatility of time-charter tanker freight rates when compared to their equivalent spot tanker freight rates is documented both in the descriptive statistics reported in Table 1 of this paper and in the relevant literature on the issue (Kavussanos, 1996b; Kavussanos and Nomikos, 2003). As expected GARCH models employed in this paper exhibit overall better accuracy when drawing volatility forecasts for the time-charter contracts. The results reported in Table 2 also enable comparisons between different GARCH specifications and exogenous variables used. Notably, when using the benchmark GARCH models, i.e. without the inclusion of any exogenous variable, the IGARCH specification exhibits the lowest MAE and MSE metrics in absolute values across all GARCH specifications and freight rates examined, with the exception of spot freight rates for small tankers (Aframax and MR).

\section{[INSERT TABLE 2 HERE]}

Next, Tables 3, 4 and 5 compare the volatility forecasting accuracy of the benchmark GARCH models and the GARCH-X models which include one out of the three oil-related exogenous variables, i.e. oil supply shock, aggregate oil demand shock and precautionary oil-specific demand shock, respectively. Each entry of Tables 3 to 5 reports the ratio of the MAE and MSE statistics of the GARCH-X model over the benchmark model. ${ }^{15}$ The values in brackets - below each ratio reported - correspond to the p-values of the Diebold Mariano (1995) test. The null hypothesis of the DM test is that of equal forecasting performance

\footnotetext{
${ }^{15}$ Table A1 in the Appendix reports the ratio of the RMSE metric of the GARCH-X model over the benchmark model. RMSE is defined as:

$$
R M S E=\sqrt{M S E}
$$

where MSE is defined in Equation 9. Tables A2 up to A5 in the Appendix report the values of MAE, MSE and RMSE error metrics.
} 
between the two competing models, i.e. the GARCH-X model and the benchmark GARCH model estimated. The positive or negative signs included in the brackets denote which model out of the two competing models performs better in terms of statistical significance. Specifically, a positive sign $(+)$ indicates that the GARCH-X model is superior in drawing volatility forecasts over the benchmark GARCH model, while a negative sign (-) denotes the opposite.

Table 3 presents the ratios of the MAE and the MSE statistics between each one of the GARCH-X models which include oil supply shock as an exogenous variable and the benchmark model. As observed, based on the MAE statistic, in all cases the benchmark models produce worse forecasts (higher MAE) than the augmented models, i.e. the ratio reported is below unity. However, there are three exceptions to this, namely for the Spot VLCC tanker freight rates when using the IGARCH and CGARCH models and for the Spot Aframax tanker freight rates when using the CGARCH model. ${ }^{16}$ Accordingly, the p-values of the DM test reveal that in 29 cases out of a total of 48 (almost 60\%) the null hypothesis of equal forecasting accuracy in statistical terms between the two competing models is rejected at the $5 \%$ significance level. In 28 cases out of the 29 where the null hypothesis of equal forecasting accuracy has been rejected, we observe a positive $(+)$ sign suggesting that the alternative model - which includes the oil supply shock as an exogenous variable - outperforms the benchmark model. Thus, including the structural shock of oil supply as an exogenous variable in the GARCH-X models estimated improves overall their ability to forecast the volatility of tanker freight rates in the majority of the cases examined. In turn, when using the MSE statistic instead of the MAE statistic, the results appear qualitatively equivalent, i.e. in almost all cases apart from the same three exceptions as before, the benchmark model performs worse (higher MSE) than the alternative model. However, according to the Diebold-Mariano test, in 14 out of 48 cases (almost 29\%) the null hypothesis of equal forecasting accuracy in statistical terms between the competing models is rejected at the $5 \%$ significance level. In 13 out of these 14 cases, we observe a positive sign $(+)$ indicating that the alternative model which includes the oil supply shock as an exogenous variable outperforms the benchmark model. Therefore, our results on whether the inclusion of oil supply as an exogenous variable in the examined GARCH models improves freight rate volatility forecasts point to the fact that there is a weak overall

\footnotetext{
${ }^{16}$ The only model whose forecast performance could not be examined and compared with the benchmark models is the CGARCH of the 1-year time-charter VLCC due to non-convergence in the CGARCH estimation.
} 
improvement in volatility forecasting of tanker freight rates when oil supply shock is added in a GARCH model as an exogenous variable; which appears even weaker if we use the MSE statistic to evaluate the forecasting accuracy of the models employed.

\section{[INSERT TABLE 3 HERE]}

In turn, Table 4 reports the same results as in Table 3 , but this time the alternative models include the aggregate oil demand shock as an exogenous variable in the variance equation. Based on the MAE statistic, in 37 out of 48 cases (77\%) the null hypothesis of the DM test is rejected at the $5 \%$ significance level. In 33 out of these 37 cases, the alternative model including aggregate oil demand as an exogenous variable outperforms the benchmark model in statistical terms. These results are overall similar when using the MSE statistic instead of the MAE statistic as above. Specifically, in 33 out of 48 cases (almost 69\%) the null hypothesis of the DM test is rejected at the $5 \%$ significance level. In 29 out of these 33 cases, the alternative model including aggregate oil demand as an exogenous variable outperforms the benchmark model in statistical terms. Such results, suggest that including the aggregate oil demand shock as an exogenous variable in a GARCH-X model significantly increases its forecasting power for both the spot and time-charter tanker freight rates and across vessel sizes.

\section{[INSERT TABLE 4 HERE]}

Finally, Table 5 reports the same results but this time the alternative models include the precautionary oil-specific demand shock as an exogenous variable in the variance equation. Based on the MAE statistic, in 37 out of 48 cases (almost $77 \%$ ) the null hypothesis of the DM test is rejected at the 5\% significance level. In 34 out of these 37 cases, the alternative model including oil-specific demand shock as an exogenous variable outperforms the benchmark model in statistical terms. The results are very similar when using the MSE statistic instead of the MAE statistic as above. Specifically, in 35 out of 48 cases (almost $73 \%$ ) the null hypothesis of the DM test is rejected at the 5\% significance level. In 32 out of these 35 cases, the alternative model including oil-specific demand shock as an exogenous variable outperforms the benchmark model in statistical terms. Such results, suggest that including the precautionary oil-specific demand shock as an exogenous variables in GARCH models significantly improves their volatility forecasting performance for both the spot and time-charter tanker freight rates and across vessel sizes. ${ }^{17}$

\footnotetext{
${ }^{17}$ The results are qualitatively the same if we allow for the sample used to change over time. Specifically,
} 


\section{[INSERT TABLE 5 HERE]}

Overall, these results indicate that the structural shocks of aggregate oil demand and precautionary oil-specific demand shocks contain information which significantly improves the volatility forecasting accuracy of a wide set of popular GARCH models. In contrast, the inclusion of oil supply shock leads to only weak improvements in forecasting volatility in the tanker freight markets. In addition, results reported in Tables A2 to A5 of the appendix reveal the following: first, when using the GARCH models without any exogenous variable (Table A2), the long-memory IGARCH and CGARCH models provide the most accurate volatility forecasts across the spot and 1-year time-charter rates examined, i.e. the smallest values for the MAE, MSE and RMSE metrics. Second, when including one of the three oil price shocks previously defined as an exogenous variable in the GARCH models estimated (Tables A3 up to A5), the asymmetric EGARCH and TGARCH models exhibit the highest overall forecasting accuracy followed by the traditional GARCH model for the majority of the spot freight rates examined; while, the long-memory IGARCH and CGARCH models provide the most accurate volatility forecasts for the majority of the 1-year time-charter freight rates examined.

\section{Discussion of the results}

The inclusion of oil price as an exogenous variable in GARCH models has been documented to convey relevant information for the tanker freight rate market that would not otherwise be captured (Kavussanos, 1996a,b; Drobetz et al., 2012). However, as the empirical results of this paper reveal such relevant information is subject to the origin of the oil price change. The results reported in this study reveal that the inclusion of oil price shocks as exogenous variables to a wide set of popular GARCH-X models significantly improves their forecasting power for both the spot and 1-year time charter tanker freight rates. Specifically, both the aggregate oil demand shock and the precautionary oil-specific demand shock lead to higher forecasting power as measured by the MAE and MSE statistics. The statistical significance of the superior ability of these models - over the benchmark model which we assess the forecast performance of the models over time by calculating the cumulative average squared and absolute errors for each GARCH specification and across all tanker vessels examined. With the exception of EGARCH and CGARCH cases, this exercise provides additional evidence confirming that adding oil price shocks of different origin as exogenous variable in GARCH models improves significantly their forecasting performance over time. These results are available from the authors upon request. 
includes no exogenous variables - is also confirmed in statistical terms with the use of the Diebold-Mariano statistic.

These results confirm our prior expectations that oil price shocks of different origin contain different kind of information regarding the underlying commodity market of oil which lead to better forecasts of the transportation cost of this commodity, i.e. the tanker freight rates. Specifically, the results of this paper reveal that an index of global real economic activity - reflecting the aggregate oil demand - as developed by Kilian (2009) contains significant information that can help GARCH models to predict tanker freight rates in a more accurate way on average. This result can be attributed to the fact that, for example, a demand increase due to a shock in the global real economic activity causes a boost in the demand for oil shipping transportation service, as higher energy resources are needed to fuel the higher level of production. In a similar manner, an increase in the oilspecific demand (precautionary) that increases the inventory levels due to an unexpected oil price increase also conveys significant information when drawing forecasts of tanker freight rates through a GARCH-X model. This can be attributed to the fact that higher demand due to expectations of an oil price increase leads to higher demand for oil shipping transportation service.

The improvement of tanker freight rates volatility forecasts appears higher overall when including the precautionary oil-specific demand shock (Table 5) rather than including the global aggregate oil demand shock (Table 4). Furthermore, the inclusion of oil demand in the variance equation of the GARCH models results into better forecasts for the timecharter markets, whereas the inclusion of oil prices leads to better forecasts for the spot market. This finding is in accordance to expectations, as fluctuations in oil price shocks are expected to be more relevant to the short-run investment horizon of the spot market. In contrast, oil demand shocks appear more relevant for the time-charter market, which is generally linked with a longer investment horizon.

Overall, when using the MAE instead of MSE statistic, the GARCH models estimated exhibit better forecasting ability across the spot and 1-yr time-charter tanker freight rates. This is expected as the MSE is generally a stricter forecasting power statistic. Forecasts for the 1yr time-charter tanker freight rates are better overall when compared to the spot tanker freight rates, when including the aggregate demand oil shock (Table 4) or the oilspecific demand shock (Table 5) as exogenous variables in the variance equation. This can be attributed to the lower volatility of the time-charter contracts when compared to their spot market equivalents. 
For the spot tanker freight rates, the GARCH-X models estimated, exhibit better forecasting power in terms of the MAE statistic when using either the aggregate demand oil shock (Table 4) instead of the oil-specific demand shock (Table 5) as an exogenous variable in the variance equation. However, the opposite is true when using the MSE statistic. For the 1yr time-charter tanker freight rates, the results are almost identical across the MAE and MSE statistics and the inclusion of the aggregate oil demand and oil-specific demand shocks. Such results reveal that, when assessing the forecasting power of GARCH-X models including oil price shocks of different origin, the selection of the relevant statistical criterion is of crucial importance.

Despite the fact that assessing the forecasting accuracy for tanker freight rates of different GARCH models estimated is not the primary purpose of this paper, the results reported enable such a comparison. The estimated GARCH models capture the stylized facts of financial and shipping time series, such as clustering, asymmetry effects and long memory effects. Overall, the results reported point to better forecasting performance for the long memory genre of GARCH models (Ding et al., 1993; Bollerslev and Mikkelsen, 1996; Engle and Lee, 1999). Recently, long memory properties were explored by Arouri, Hammoudeh, Lahiani, and Nguyen (2012) on the volatility dynamics of precious metals and by Huang, Liu, and Wang (2016) who emphasized the importance of capturing the long memory feature of financial returns by proposing a Heterogenous Autoregressive (HAR)GARCH specification. Conversely, the asymmetry effects are not to be ignored within the modeling process; as Arouri et al. (2012) mention, asymmetry is found to be relevant in the dynamics of precious metals, while Chkili, Hammoudeh, and Nguyen (2014) acknowledge the importance of long memory as well as asymmetry in commodity markets. To this end, this paper also reports that asymmetric GARCH models produce better forecasts when the precautionary oil-specific demand shock is included in the variance equation of the model specification across the vessel sizes VLCC, Suezmax, Aframax, yet overall the long memory GARCH models perform better. Forecasting in the shipping industry and energy markets, which are directly linked to the financial markets, has gained popularity as demonstrated by a large number of studies (Kavussanos, 1996b; Jing, Marlow, and Wangi, 2008; Drobetz et al., 2012; Wang and Wu, 2012; Alizadeh, 2013). Such studies are aided by the tools and methodological approaches developed for forecasting shipping freight rates; while in the general finance literature a number of studies have included various economic and other parameters in the modeling process, such as implied volatility, captured by the Volatility Index (VIX), and trading volume (Lamoureux and Lastrapes, 1990; Blair, Poon, and Tay- 
lor, 2001; Fuertes, Kalotychou, and Todorovic, 2015; Kambouroudis and McMillan, 2016; Chao, 2016).

\section{Conclusion}

This paper examines whether the inclusion of oil price shocks of different origin as exogenous variables in a wide set of GARCH-X models improves the accuracy of their volatility forecasts for spot and 1-year time-charter tanker freight rates. Overall, the reported results suggest that the inclusion of aggregate oil demand shocks and precautionary oil-specific demand shocks significantly improves the accuracy of the volatility forecasts drawn; while the inclusion of oil supply shock leads to only weak improvements in forecasting volatility in the tanker freight markets. These results, appear robust across freight rate contracts, i.e. the spot and 1-year time-charter tanker freight rates; and vessel sizes, i.e. VLCC, Suezmax, Aframax and MR. This study contributes to the growing literature of modeling and forecasting the volatility of freight rate markets by providing robust and novel empirical evidence revealing the relevance of oil price shocks in drawing volatility forecasts for the tanker freight markets. The empirical findings reported bear important implications for companies operating in the oil and shipping industries, such as shipping companies, oil importers and banks, in their effort to quantify and hedge their risks in the tanker freight rate markets. 


\section{References}

Adland, R. and K. Cullinane (2006, May). The non-linear dynamics of spot freight rates in tanker markets. Transportation Research Part E: Logistics and Transportation Review 42(3), 211-224.

Alexandridis, G., M. G. Kavussanos, C. Y. Kim, D. A. Tsouknidis, and I. D. Visvikis (2018, July). A survey of shipping finance research: Setting the future research agenda. Transportation Research Part E: Logistics and Transportation Review 115, 164-212.

Alexandridis, G., S. Sahoo, and I. Visvikis (2017). Economic information transmissions and liquidity between shipping markets: New evidence from freight derivatives. Transportation Research Part E 98, 82-104.

Alizadeh, A. (2013). Trading volume and volatility in the shipping forward freight market. Transportation Research Part E 49, 250-265.

Alizadeh, A., K. Kappou, D. Tsouknidis, and I. Visvikis (2015). Liquidity effects and FFA returns in the international shipping derivatives market. Transportation Research Part E 76, 58-75.

Alizadeh, Amir, H. and N. K. Nomikos (2011). Dynamics of the term structure and volatility of shipping freight rates. Journal of Transportation and Policy 45, 105-128.

Andersen, T. G. and T. Bollerslev (1998). Answering the Skeptics: Yes, Standard Volatility Models do Provide Accurate Forecasts. International Economic Review 39, 885-905.

Arouri, M., S. Hammoudeh, A. Lahiani, and D. Nguyen (2012). Long memory and structural breaks in modeling the return and volatility dynamics of precious metals. The Quarterly Review of Economics and Finance 52, 207-218.

Batchelor, R., A. Alizadeh, and I. Visvikis (2007). Forecasting spot and forward prices in the international freight market. International Journal of Forecasting 23, 101-114.

Blair, B., S. Poon, and S. Taylor (2001). Forecasting S\&P 100 volatility: the incremental content of implied volatilities and high-frequency index returns. Journal of Econometrics $105(1), 5-26$. 
Bollerslev, T. (1986). Generalized Autoregressive conditional heteroskedasticity. Journal of Econometrics 31, 307-327.

Bollerslev, T. and H. Mikkelsen (1996). Modeling and pricing long memory in stock market volatility. Journal of Econometrics 73(1), 151-184.

British Petroleum (2015). Statistical review of world energy 2015.

Chao, S. (2016). Do economic variables improve bond return volatility forecasts? International Review of Economics and Finance 46, 10-26.

Chen, F., Y. Miao, K. Tian, X. Ding, and T. Li (2017, May). Multifractal cross-correlations between crude oil and tanker freight rate. Physica A: Statistical Mechanics and its Applications 474, 344-354.

Chen, Y. and S. Wang (2004). The empirical evidence of the leverage effect on volatility in international bulk shipping market. Maritime Policy and Management 31(2), 109-124.

Chkili, W., S. Hammoudeh, and D. Nguyen (2014). Volatility forecasting and risk management for commodity markets in the presence of asymmetry and long memory. Energy Economics 41, 1-18.

Cullinane, K. P. B. (1992). A short-term adaptive forecasting model for Biffex speculation: A Box-Jenkins approach. Maritime Policy and Management 19, 91-114.

Cullinane, K. P. B., K. J. Mason, and M. B. Cape (1992). A comparison of models for forecasting the Baltic freight index: Box-Jenkins revisited. International Journal of Maritime Economics 1(2), 15-39.

Dickey, D. A. and W. A. Fuller (1981). Likelihood ratio statistics for autoregressive time series with a unit root. Econometrica: Journal of the Econometric Society 49(4), 10571072.

Diebold, F. X. and R. S. Mariano (1995). Comparing predictive accuracy. Journal of Business and Economics Statistics 13(3), 253-263.

Ding, Z., R. F. Engle, and C. W. J. Granger (1993). A long memory property of stock returns and a new model. Journal of Empirical Finance 1, 83-103. 
Drobetz, W., T. Richter, and M. Wambach (2012). Dynamics of the time-varying volatility in the dry bulk and tanker freight markets. Applied Financial Economics 22, 1367-1384.

Engle, Robert, F. (1982). Autoregressive conditional heteroscedasticity with estimates of the variance of United Kingdom inflation. Econometrica 50, 987-1007.

Engle, R. F. and T. Bollerslev (1986, January). Modelling the persistence of conditional variances. Econometric Reviews 5(1), 1-50.

Engle, R. F. and G. G. J. Lee (1999). A permanent and transitory component model of stock return volatility. In R. F. Engle and H. White (Eds.), Cointegration, causality and forecasting: a festschrift in honour of Clive $W J$ Granger. Oxford: Oxford University Press.

Fuertes, A., E. Kalotychou, and N. Todorovic (2015). Daily volume, intraday and overnight returns for volatility prediction: probability or accuracy? Review of Quantitative Analysis and Accounting 45, 251-278.

Glosten, L., T. Jagannathan, and D. Runkle (1993). On the relation between expected value and the volatility of the nominal excess return on stocks. The Journal of Finance 48 , $1779-1801$.

Goncalves, S. and L. Kilian (2004). Bootstrapping autoregressions with conditional heteroskedasticity of unknown form. Journal of Econometrics 123(1), 89-120.

Hamilton, J. (1983). Oil and the Macroeconomy since World War II. Journal of Political Economy 91(2), 228-248.

Huang, Z., H. Liu, and T. Wang (2016). Modeling long memory volatility using realized measures of volatility: A realized HAR GARCH model. Economic modelling 52B, 812821.

Jing, L., P. Marlow, and H. Wangi (2008). An analysis of freight rate volatility in dry bulk shipping markets. Maritime Policy and Management 35(3), 237-251.

Kambouroudis, D. and D. McMillan (2016). Does Vix or volume improve volatility forecasts? Applied Economics 48(13), 1210-1228.

Kavussanos, Manolis, G. (1996a). Comparisons of volatility in the dry-cargo ship sector. Journal of Transport Economics and Policy 30, 67-82. 
Kavussanos, Manolis, G. (1996b). Price risk modelling of different size vessels in the tanker industry using autoregressive conditional heteroskedasticity $(\mathrm{ARCH})$ models. The Logistics and Transportation Review 32, 161-176.

Kavussanos, Manolis, G. and N. K. Nomikos (2003). Price discovery, causality and forecasting in the freight futures market. Review of Derrivatives Research 6(3), 203-230.

Kavussanos, Manolis, G. and I. D. Visvikis (2004). Market interactions in returns and volatilities between spot and forward shipping freight markets. Journal of Banking and Finance 28(8), 2015-2049.

Kavussanos, Manolis, G., I. D. Visvikis, and D. Dimitrakopoulos (2014). Economic spillovers between related derivatives markets: The case of commodity and freight markets. Transportation Research Part E 68, 79-102.

Kavussanos, M. and I. Visvikis (2006). Derivatives and Risk Management in Shipping. Witherbys Publishing Limited \& Seamanship International.

Kilian, L. (2009). Not all oil price shocks are alike: disentangling demand and supply shocks in the crude oil market. American Economic Review 99(3), 1053-1069.

Kilian, L. and H. Lutkepohl (2017). Structural Vector Autoregressive Analysis. Cambridge University Press.

Kilian, L. and C. Park (2009). The impact of oil price shocks on the U.S. stock market. International Economic Review 50(4), 1267-1287.

Lambertides, N., C. Savva, and D. Tsouknidis (2017). The effects of oil price shocks on U.S. stock order flow imbalances and stock returns. Journal of International Money and Finance 74, 137-146.

Lamoureux, C. and W. Lastrapes (1990). Heteroskedasticity in stock return data: volume versus GARCH effects. The Journal of Finance 45(1), 221-229.

Magkonis, G. and D. A. Tsouknidis (2017, July). Dynamic spillover effects across petroleum spot and futures volatilities, trading volume and open interest. International Review of Financial Analysis 52(Supplement C), 104-118. 
Mincer, J. and V. Zarnowitz (1969). The evaluation of economic forecasts. In J. Mincer (Ed.), Economic Forecasts and Expectations, pp. 3-46. New York: Columbia University Press.

Nelson, D. B. (1991). Conditional heteroskedasticity in asset returns: a new approach. Econometrica 59, 347-370.

Pagan, A. R. and G. W. Schwert (1990). Alternative models for conditional stock Volatility. Journal of Econometrics 45, 267-290.

Patton, A. J. (2011). Volatility forecast comparison using imperfect volatility proxies. Journal of Econometrics 160(1), 246-256.

Phillips, P. C. B. and P. Perron (1988, June). Testing for a unit root in time series regression. Biometrika 75(2), 335-346.

Poon, S. and C. W. J. Granger (2003). Forecasting volatility in financial markets: A Review. Journal of Economic Literature 41(2), 478-539.

Shi, W., Z. Yang, and X. Li (2013). The Impact of Crude Oil Price on the Tanker Market. Maritime Policy and Management 40(4), 309-322.

Stopford, M. (2009). Maritime Economics. Routledge.

Tsouknidis, Dimitris, A. (2016). Dynamic Volatility spillovers across shipping freight markets. Transportation Research Part E 91, 90-111.

UNCTAD (2017). Review of Maritime Transport.

Wang, Y. and C. Wu (2012). Forecasting energy market volatility using GARCH models: Can multivariate models beat univariate models? Energy Economics 24, 2167-2181.

West, K. D. (1996). Asymptotic inference about predictive ability. Econometrica 64, 1067-1084.

Zhou, W.-X. (2012, February). Finite-size effect and the components of multifractality in financial volatility. Chaos, Solitons $\&$ Fractals 45(2), 147-155. 
Table 1: Descriptive statistics for the first logarithmic differences of the time series examined.

\begin{tabular}{|c|c|c|c|c|c|c|c|c|c|c|c|}
\hline & SPOT_VLCC & SPOT_SUEZ & SPOT_AFRA & SPOT_MR & TC1_VLCC & TC1_SUEZ & TC1_AFRA & TC1_MR & OIL_DEMAND & OIL_PRICE & OIL_PROD \\
\hline Mean & 0.000387 & 0.000193 & $-8.57 \mathrm{E}-05$ & -0.000294 & 0.000747 & 0.000406 & $9.55 \mathrm{E}-05$ & 0.000211 & 1.364401 & 0.001138 & 0.000383 \\
\hline Median & -0.003630 & 0.005141 & -0.010577 & -0.006502 & 0.000000 & 0.000000 & 0.000000 & 0.000000 & -2.375000 & 0.005013 & 0.000476 \\
\hline Maximum & 0.525292 & 0.546734 & 0.516857 & 0.300492 & 0.164611 & 0.181844 & 0.085172 & 0.098486 & 66.40000 & 0.166355 & 0.019006 \\
\hline Minimum & -0.519372 & -0.600643 & -0.533188 & -0.326512 & -0.097090 & -0.128408 & -0.082741 & -0.058281 & -134.0000 & -0.159197 & -0.026242 \\
\hline Std. Dev. & 0.148353 & 0.147817 & 0.133636 & 0.078763 & 0.035027 & 0.028268 & 0.021716 & 0.017828 & 28.48381 & 0.037302 & 0.003966 \\
\hline Skewness & 0.204802 & -0.170910 & 0.196194 & 0.319509 & 0.894669 & 1.289478 & 0.331315 & 0.920065 & -0.158786 & -0.534465 & -0.710881 \\
\hline Kurtosis & 4.442932 & 5.183219 & 5.965301 & 4.784801 & 6.000347 & 11.54712 & 5.919901 & 8.621402 & 4.478881 & 5.696047 & 10.19399 \\
\hline Jarque-Bera & 30.37267 & 65.92438 & 120.7842 & 48.51709 & 164.7515 & 1076.007 & 121.0261 & 472.3141 & 30.88723 & 113.2018 & 719.2398 \\
\hline Probability & 0.000000 & 0.000000 & 0.000000 & 0.000000 & 0.000000 & 0.000000 & 0.000000 & 0.000000 & 0.000000 & 0.000000 & 0.000000 \\
\hline Sum & 0.125463 & 0.062396 & -0.027759 & -0.095179 & 0.242125 & 0.131569 & 0.030949 & 0.068355 & 442.0660 & 0.367644 & 0.123082 \\
\hline Sum Sq. Dev. & 7.108809 & 7.057519 & 5.768309 & 2.003791 & 0.396281 & 0.258101 & 0.152326 & 0.102666 & 262058.8 & 0.448036 & 0.005034 \\
\hline Observations & 324 & 324 & 324 & 324 & 324 & 324 & 324 & 324 & 324 & 324 & 324 \\
\hline
\end{tabular}


Table 2: Forecast evaluation of the benchmark models for the tanker freight rates volatility.

\begin{tabular}{|c|c|c|c|c|c|c|}
\hline \multicolumn{7}{|c|}{ MAE } \\
\hline & GARCH & EGARCH & TGARCH & APARCH & IGARCH & CGARCH \\
\hline Spot VLCC & 0.040509 & 0.042888 & 0.040176 & 0.040153 & 0.032758 & 0.041788 \\
\hline Spot Suezmax & 0.046755 & 0.046502 & 0.044006 & 0.043259 & 0.042720 & 0.045417 \\
\hline Spot Aframax & 0.042617 & 0.048212 & 0.042577 & 0.045732 & 0.041125 & 0.035012 \\
\hline Spot Medium Range & 0.015547 & 0.013741 & 0.013442 & 0.012567 & 0.013154 & 0.014453 \\
\hline 1 yr TC VLCC & 0.002474 & 0.004121 & 0.002601 & 0.004967 & 0.001750 & 0.001942 \\
\hline 1 yr TC Suezmax & 0.004537 & 0.002098 & 0.001810 & 0.001734 & 0.001120 & 0.003727 \\
\hline 1 yr TC Aframax & 0.002490 & 0.002422 & 0.002131 & 0.001998 & 0.000978 & 0.002894 \\
\hline 1 yr TC Medium Range & 0.002058 & 0.001180 & 0.002110 & 0.001066 & 0.000503 & 0.000628 \\
\hline \multicolumn{7}{|c|}{ MSE } \\
\hline & GARCH & EGARCH & TGARCH & APARCH & IGARCH & CGARCH \\
\hline Spot VLCC & 0.003024 & 0.003126 & 0.002998 & 0.003269 & 0.002480 & 0.003024 \\
\hline Spot Suezmax & 0.004120 & 0.004162 & 0.004097 & 0.004045 & 0.003924 & 0.004195 \\
\hline Spot Aframax & 0.003694 & 0.004490 & 0.003535 & 0.004180 & 0.003208 & 0.002945 \\
\hline Spot Medium Range & 0.000428 & 0.000364 & 0.000412 & 0.000350 & 0.000373 & 0.000410 \\
\hline $1 \mathrm{yr}$ TC VLCC & 1.63E-05 & $7.35 \mathrm{E}-05$ & $1.56 \mathrm{E}-05$ & $7.51 \mathrm{E}-05$ & 8.47E-06 & $9.87 \mathrm{E}-06$ \\
\hline 1 yr TC Suezmax & $8.18 \mathrm{E}-05$ & 0.000112 & $1.01 \mathrm{E}-05$ & $4.87 \mathrm{E}-05$ & $6.00 \mathrm{E}-06$ & $2.57 \mathrm{E}-05$ \\
\hline 1 yr TC Aframax & $2.97 \mathrm{E}-05$ & $1.66 \mathrm{E}-05$ & $3.33 \mathrm{E}-05$ & $1.80 \mathrm{E}-05$ & $1.28 \mathrm{E}-05$ & $1.43 \mathrm{E}-05$ \\
\hline 1 yr TC Medium Range & $1.29 \mathrm{E}-05$ & $4.38 \mathrm{E}-06$ & $1.91 \mathrm{E}-05$ & $9.87 \mathrm{E}-06$ & $1.23 \mathrm{E}-06$ & $1.70 \mathrm{E}-06$ \\
\hline
\end{tabular}

Note: This table reports the mean absolute error (MAE) and mean squared error (MSE) for the benchmark GARCH models. The MAE and MSE are defined in Eqs. (8) and (9), respectively. The sample period runs from January 1990 to December 2016. The tanker freight rates volatility forecasts have been obtained recursively for the period January 2004 to December 2016. 
Table 3: Forecast evaluation of tanker freight rates volatility using oil supply shock as an exogenous variable.

\begin{tabular}{|c|c|c|c|c|c|c|}
\hline \multicolumn{7}{|c|}{ MAE } \\
\hline \multirow{3}{*}{ Spot VLCC } & GARCH & EGARCH & TGARCH & APARCH & IGARCH & CGARCH \\
\hline & 0.7778 & 0.9082 & 0.8393 & 0.8937 & 1.1268 & 1.6855 \\
\hline & $(0.000+)$ & $(0.373)$ & $(0.000+)$ & $(0.106)$ & $(0.088-)$ & $(0.000-)$ \\
\hline \multirow[t]{2}{*}{ Spot Suezmax } & 0.8724 & 0.6789 & 0.8836 & 0.7827 & 0.8817 & 0.8584 \\
\hline & $(0.143)$ & $(0.017+)$ & $(0.168)$ & $(0.018+)$ & $(0.296)$ & $(0.009+)$ \\
\hline \multirow[t]{2}{*}{ Spot Aframax } & 0.8198 & 0.6917 & 0.7818 & 0.6619 & 0.8751 & 1.0233 \\
\hline & $(0.150)$ & $(0.048+)$ & $(0.028+)$ & $(0.060+)$ & $(0.348)$ & $(0.516)$ \\
\hline \multirow[t]{2}{*}{ Spot Medium Range } & 0.5783 & 0.5869 & 0.6598 & 0.6339 & 0.6902 & 0.9313 \\
\hline & $(0.000+)$ & $(0.000+)$ & $(0.000+)$ & $(0.000+)$ & $(0.089+)$ & $(0.181)$ \\
\hline \multirow[t]{2}{*}{1 yr TC VLCC } & 0.6407 & 0.4283 & 0.6231 & 0.3415 & 0.9347 & NA \\
\hline & $(0.000+)$ & $(0.000+)$ & $(0.000+)$ & $(0.000+)$ & $(0.019+)$ & \\
\hline \multirow[t]{2}{*}{1 yr TC Suezmax } & 0.3764 & 0.8409 & 0.5929 & 0.5609 & 0.8918 & 0.2884 \\
\hline & $(0.001+)$ & $(0.000+)$ & $(0.000+)$ & $(0.118)$ & $(0.268)$ & $(0.008+)$ \\
\hline \multirow[t]{2}{*}{1 yr TC Aframax } & 0.4495 & 0.3552 & 0.5155 & 0.4315 & 0.6917 & 0.2884 \\
\hline & $(0.012+)$ & $(0.011+)$ & $(0.087+)$ & $(0.003+)$ & $(0.103)$ & $(0.002+)$ \\
\hline \multirow[t]{4}{*}{1 yr TC Medium Range } & 0.3253 & 0.5992 & 0.4461 & 0.7417 & 0.9444 & 0.8217 \\
\hline & $(0.020+)$ & $(0.000+)$ & $(0.000+)$ & $(0.102)$ & $(0.203)$ & $(0.002+)$ \\
\hline & & $\mathrm{M}_{s}^{\mathrm{s}}$ & & & & \\
\hline & GARCH & EGARCH & TGARCH & APARCH & IGARCH & CGARCH \\
\hline \multirow[t]{2}{*}{ Spot VLCC } & 0.9122 & 1.0229 & 0.9550 & 0.8446 & 1.0887 & 2.5936 \\
\hline & $(0.100)$ & $(0.887)$ & $(0.451)$ & $(0.064+)$ & $(0.136)$ & $(0.001-)$ \\
\hline \multirow[t]{2}{*}{ Spot Suezmax } & 0.9101 & 0.8504 & 0.8940 & 0.9401 & 0.8926 & 0.8210 \\
\hline & $(0.455)$ & $(0.228)$ & $(0.347)$ & $(0.655)$ & $(0.365)$ & $(0.068+)$ \\
\hline \multirow[t]{2}{*}{ Spot Aframax } & 0.8477 & 0.7716 & 0.8742 & 0.7107 & 0.9690 & 1.0508 \\
\hline & $(0.378)$ & $(0.359)$ & $(0.401)$ & $(0.219)$ & $(0.759)$ & $(0.259)$ \\
\hline \multirow[t]{2}{*}{ Spot Medium Range } & 0.6487 & 0.6675 & 0.6551 & 0.6777 & 0.6828 & 0.8573 \\
\hline & $(0.001+)$ & $(0.003+)$ & $(0.004+)$ & $(0.001+)$ & $(0.179)$ & $(0.142)$ \\
\hline \multirow[t]{2}{*}{1 yr TC VLCC } & 0.4762 & 0.1540 & 0.4967 & 0.1178 & 0.9232 & NA \\
\hline & $(0.003+)$ & $(0.057+)$ & $(0.000+)$ & $(0.028+)$ & $(0.000+)$ & \\
\hline \multirow[t]{2}{*}{1 yr TC Suezmax } & 0.8465 & 0.7387 & 0.4542 & 0.0972 & 0.7535 & 0.2094 \\
\hline & $(0.844)$ & $(0.237)$ & $(0.005+)$ & $(0.221)$ & $(0.146)$ & $(0.016+)$ \\
\hline \multirow[t]{2}{*}{1 yr TC Aframax } & 0.1544 & 0.2675 & 0.1652 & 0.1449 & 0.1068 & 0.6597 \\
\hline & $(0.129)$ & $(0.159)$ & $(0.240)$ & $(0.027+)$ & $(0.077+)$ & $(0.619)$ \\
\hline \multirow[t]{2}{*}{1 yr TC Medium Range } & 0.1251 & 0.3765 & 0.1141 & 0.1912 & 0.9232 & 0.7755 \\
\hline & $(0.085+)$ & $(0.032+)$ & $(0.047+)$ & $(0.069+)$ & $(0.107)$ & $(0.173)$ \\
\hline
\end{tabular}

Note: Entries report the ratio of the mean absolute error (MAE) and mean squared error (MSE) of the GARCH models augmented with oil supply shock over the same values for the benchmark model, i.e. without the oil supply shock. The sample period runs from January 1990 to December 2016. The forecasts have been obtained recursively for the period January 2004 to December 2016. P-values of the Diebold-Mariano (DM) test are reported in brackets. The null hypothesis of the DM test is that of equal predictive ability between the augmented GARCH models with oil supply shock and the benchmark GARCH model. The positive (negative) sign indicates that the competing (benchmark) model has superior performance in drawing volatility forecasts. The value "NA" denotes that the GARCH model has not converged and for this reason it was not feasible to obtain volatility forecasts. 
Table 4: Forecast evaluation of tanker freight rates volatility using aggregate oil demand shock as an exogenous variable.

\begin{tabular}{|c|c|c|c|c|c|c|}
\hline \multicolumn{7}{|c|}{ MAE } \\
\hline \multirow{3}{*}{ Spot VLCC } & GARCH & EGARCH & TGARCH & $\mathrm{APARCH}$ & IGARCH & $\mathrm{CGARCH}$ \\
\hline & 0.7874 & 0.8914 & 0.8065 & 0.8987 & 1.1058 & 1.3066 \\
\hline & $(0.000+)$ & $(0.110)$ & $(0.000+)$ & $(0.040+)$ & $(0.001-)$ & $(0.027-)$ \\
\hline \multirow[t]{2}{*}{ Spot Suezmax } & 0.7976 & 0.8535 & 0.8079 & 0.7840 & 0.8946 & 0.8203 \\
\hline & $(0.012+)$ & $(0.471)$ & $(0.027+)$ & $(0.027+)$ & $(0.379)$ & $(0.001+)$ \\
\hline \multirow[t]{2}{*}{ Spot Aframax } & 0.7875 & 0.6134 & 0.7921 & 0.6867 & 0.8317 & 2.1419 \\
\hline & $(0.080+)$ & $(0.036+)$ & $(0.041+)$ & $(0.060+)$ & $(0.158)$ & $(0.000-)$ \\
\hline \multirow[t]{2}{*}{ Spot Medium Range } & 0.5908 & 0.6113 & 0.6479 & 0.6589 & 0.7132 & 1.8793 \\
\hline & $(0.000+)$ & $(0.000+)$ & $(0.000+)$ & $(0.000+)$ & $(0.113)$ & $(0.000-)$ \\
\hline \multirow[t]{2}{*}{1 yr TC VLCC } & 0.6436 & 0.4594 & 0.6303 & 0.3786 & 0.9325 & 0.8581 \\
\hline & $(0.000+)$ & $(0.000+)$ & $(0.000+)$ & $(0.000+)$ & $(0.022+)$ & $(0.001+)$ \\
\hline \multirow[t]{2}{*}{1 yr TC Suezmax } & 0.2288 & 0.5754 & 0.6413 & 0.5919 & 0.9089 & 0.3702 \\
\hline & $(0.000+)$ & $(0.102)$ & $(0.000+)$ & $(0.133)$ & $(0.055+)$ & $(0.013+)$ \\
\hline \multirow[t]{2}{*}{1 yr TC Aframax } & 0.3259 & 0.3777 & 0.5515 & 0.4220 & 0.6730 & 0.3515 \\
\hline & $(0.002+)$ & $(0.015+)$ & $(0.038+)$ & $(0.002+)$ & $(0.024+)$ & $(0.014+)$ \\
\hline \multirow[t]{2}{*}{1 yr TC Medium Range } & 0.3414 & 0.5090 & 0.3924 & 0.5538 & 0.9450 & 0.7281 \\
\hline & $(0.011+)$ & $(0.000+)$ & $(0.000+)$ & $(0.034+)$ & $(0.201)$ & $(0.001+)$ \\
\hline \multicolumn{7}{|c|}{ MSE } \\
\hline \multirow{3}{*}{ Spot VLCC } & GARCH & EGARCH & TGARCH & APARCH & IGARCH & CGARCH \\
\hline & 0.9026 & 1.0172 & 0.9060 & 0.8483 & 1.1671 & 1.7369 \\
\hline & $(0.038+)$ & $(0.898)$ & $(0.030+)$ & $(0.036+)$ & $(0.001-)$ & $(0.018-)$ \\
\hline \multirow[t]{2}{*}{ Spot Suezmax } & 0.8945 & 2.2725 & 0.8841 & 0.9335 & 0.9200 & 0.8067 \\
\hline & $(0.338)$ & $(0.337)$ & $(0.380)$ & $(0.524)$ & $(0.511)$ & $(0.013+)$ \\
\hline \multirow[t]{2}{*}{ Spot Aframax } & 0.7997 & 0.6434 & 0.8158 & 0.7160 & 0.9104 & 3.4540 \\
\hline & $(0.262)$ & $(0.045+)$ & $(0.036+)$ & $(0.202)$ & $(0.318)$ & $(0.000-)$ \\
\hline \multirow[t]{2}{*}{ Spot Medium Range } & 0.6399 & 0.7287 & 0.6225 & 0.7358 & 0.6840 & 3.0859 \\
\hline & $(0.001+)$ & $(0.041+)$ & $(0.003+)$ & $(0.002+)$ & $(0.017+)$ & $(0.011-)$ \\
\hline \multirow[t]{2}{*}{1 yr TC VLCC } & 0.4879 & 0.2386 & 0.5076 & 0.1324 & 0.9321 & 0.8701 \\
\hline & $(0.004+)$ & $(0.083+)$ & $(0.000+)$ & $(0.031+)$ & $(0.020+)$ & $(0.003+)$ \\
\hline \multirow[t]{2}{*}{1 yr TC Suezmax } & 0.0538 & 0.0840 & 0.5030 & 0.1053 & 0.7395 & 0.2425 \\
\hline & $(0.024+)$ & $(0.268)$ & $(0.002+)$ & $(0.225)$ & $(0.081+)$ & $(0.019+)$ \\
\hline \multirow[t]{2}{*}{1 yr TC Aframax } & 0.0727 & 0.2846 & 0.1654 & 0.1423 & 0.1214 & 0.6539 \\
\hline & $(0.034+)$ & $(0.045+)$ & $(0.228)$ & $(0.023+)$ & $(0.015+)$ & $(0.592)$ \\
\hline \multirow[t]{2}{*}{1 yr TC Medium Range } & 0.1504 & 0.4370 & 0.1514 & 0.1671 & 0.9232 & 0.6792 \\
\hline & $(0.029+)$ & $(0.043+)$ & $(0.008+)$ & $(0.019+)$ & $(0.032+)$ & $(0.043+)$ \\
\hline
\end{tabular}

Note: Entries report the ratio of the mean absolute error (MAE) and mean squared error (MSE) of the GARCH models augmented with aggregate oil demand shock over the same values for the benchmark model, i.e. without the aggregate oil demand shock. The sample period runs from January 1990 to December 2016. The forecasts have been obtained recursively for the period January 2004 to December 2016 . P-values of the Diebold-Mariano (DM) test are reported in brackets. The null hypothesis of the DM test is that of equal predictive ability between the augmented GARCH models with oil supply shock and the benchmark GARCH model. The positive (negative) sign indicates that the competing (benchmark) model has superior performance in drawing volatility forecasts. 
Table 5: Forecast evaluation of tanker freight rates volatility using precautionary oil-specific demand shock as an exogenous variable.

\begin{tabular}{|c|c|c|c|c|c|c|}
\hline \multicolumn{7}{|c|}{ MAE } \\
\hline \multirow{3}{*}{ Spot VLCC } & GARCH & EGARCH & TGARCH & $\mathrm{APARCH}$ & IGARCH & $\mathrm{CGARCH}$ \\
\hline & 0.7946 & 0.7669 & 0.7999 & 0.7950 & 1.0100 & 0.7878 \\
\hline & $(0.000+)$ & $(0.000+)$ & $(0.000+)$ & $(0.001+)$ & $(0.856)$ & $(0.000+)$ \\
\hline \multirow[t]{2}{*}{ Spot Suezmax } & 0.7995 & 0.7559 & 0.8128 & 0.8358 & 0.8730 & 1.6510 \\
\hline & $(0.093+)$ & $(0.047+)$ & $(0.057+)$ & $(0.002+)$ & $(0.239)$ & $(0.000-)$ \\
\hline \multirow[t]{2}{*}{ Spot Aframax } & 0.8004 & 0.5874 & 0.8114 & 0.6227 & 0.7884 & 2.4713 \\
\hline & $(0.164)$ & $(0.030+)$ & $(0.039+)$ & $(0.045+)$ & $(0.019+)$ & $(0.000-)$ \\
\hline \multirow[t]{2}{*}{ Spot Medium Range } & 0.5952 & 0.5889 & 0.6630 & 0.6669 & 0.7331 & 2.8748 \\
\hline & $(0.000+)$ & $(0.001+)$ & $(0.000+)$ & $(0.003+)$ & $(0.048+)$ & $(0.000-)$ \\
\hline \multirow[t]{2}{*}{1 yr TC VLCC } & 0.6583 & 0.4088 & 0.6417 & 0.5222 & 0.9113 & 0.8336 \\
\hline & $(0.000+)$ & $(0.000+)$ & $(0.000+)$ & $(0.002+)$ & $(0.012+)$ & $(0.011+)$ \\
\hline \multirow[t]{2}{*}{1 yr TC Suezmax } & 0.2285 & 0.5579 & 0.6978 & 0.6043 & 0.9384 & 0.3151 \\
\hline & $(0.000+)$ & $(0.164)$ & $(0.000+)$ & $(0.173)$ & $(0.450)$ & $(0.010+)$ \\
\hline \multirow[t]{2}{*}{1 yr TC Aframax } & 0.3370 & 0.4535 & 0.5459 & 0.4695 & 0.6522 & 0.3810 \\
\hline & $(0.003+)$ & $(0.016+)$ & $(0.083+)$ & $(0.006+)$ & $(0.020+)$ & $(0.025+)$ \\
\hline \multirow[t]{2}{*}{1 yr TC Medium Range } & 0.3124 & 0.5242 & 0.4202 & 0.6896 & 0.9607 & 0.7451 \\
\hline & $(0.018+)$ & $(0.001+)$ & $(0.001+)$ & $(0.079+)$ & $(0.062+)$ & $(0.003+)$ \\
\hline \multicolumn{7}{|c|}{ MSE } \\
\hline \multirow{3}{*}{ Spot VLCC } & GARCH & EGARCH & TGARCH & APARCH & IGARCH & CGARCH \\
\hline & 0.9066 & 0.8456 & 0.8910 & 0.7814 & 1.0422 & 0.8362 \\
\hline & $(0.024+)$ & $(0.005+)$ & $(0.000+)$ & $(0.010+)$ & $(0.397)$ & $(0.001+)$ \\
\hline \multirow[t]{2}{*}{ Spot Suezmax } & 0.8453 & 0.7985 & 0.7684 & 0.8605 & 0.8987 & 2.1614 \\
\hline & $(0.266)$ & $(0.024+)$ & $(0.015+)$ & $(0.044+)$ & $(0.334)$ & $(0.000-)$ \\
\hline \multirow[t]{2}{*}{ Spot Aframax } & 0.8048 & 0.6086 & 0.8196 & 0.6318 & 0.8163 & 9.0021 \\
\hline & $(0.313)$ & $(0.032+)$ & $(0.322)$ & $(0.038+)$ & $(0.021+)$ & $(0.000-)$ \\
\hline \multirow[t]{2}{*}{ Spot Medium Range } & 0.6445 & 0.6713 & 0.6388 & 0.7457 & 0.7142 & 5.3448 \\
\hline & $(0.002+)$ & $(0.011+)$ & $(0.001+)$ & $(0.036+)$ & $(0.046+)$ & $(0.000-)$ \\
\hline \multirow[t]{2}{*}{1 yr TC VLCC } & 0.4755 & 0.1526 & 0.5168 & 0.2147 & 0.9270 & 0.7711 \\
\hline & $(0.003+)$ & $(0.040+)$ & $(0.000+)$ & $(0.043+)$ & $(0.074+)$ & $(0.016+)$ \\
\hline \multirow[t]{2}{*}{1 yr TC Suezmax } & 0.0552 & 0.0507 & 0.7112 & 0.1078 & 0.7022 & 0.2267 \\
\hline & $(0.024+)$ & $(0.271)$ & $(0.000+)$ & $(0.228)$ & $(0.028+)$ & $(0.017+)$ \\
\hline \multirow[t]{2}{*}{1 yr TC Aframax } & 0.0718 & 0.3379 & 0.1485 & 0.1487 & 0.1086 & 0.8562 \\
\hline & $(0.034+)$ & $(0.005+)$ & $(0.222)$ & $(0.028+)$ & $(0.029+)$ & $(0.852)$ \\
\hline \multirow[t]{2}{*}{1 yr TC Medium Range } & 0.1261 & 0.3798 & 0.0830 & 0.2078 & 0.9319 & 0.6844 \\
\hline & $(0.087+)$ & $(0.007+)$ & $(0.040+)$ & $(0.085+)$ & $(0.025+)$ & $(0.190)$ \\
\hline
\end{tabular}

Note: Entries report the ratio of the mean absolute error (MAE) and mean squared error (MSE) of the GARCH models augmented with precautionary oil-specific demand shock over the same values for the benchmark model, i.e. without the precautionary oil-specific demand shock. The sample period runs from January 1990 to December 2016. The forecasts have been obtained recursively for the period January 2004 to December 2016. P-values of the Diebold-Mariano (DM) test are reported in brackets. The null hypothesis of the DM test is that of equal predictive ability between the augmented GARCH models with oil supply shock and the benchmark GARCH model. The positive (negative) sign indicates that the competing (benchmark) model has superior performance in drawing volatility forecasts. 
Appendix A 
Table A1: Forecast evaluation of tanker freight rates volatility based on the relative RMSE values for GARCH-X models against the benchmark GARCH.

\begin{tabular}{|c|c|c|c|c|c|c|}
\hline & GARCH & EGARCH & TGARCH & APARCH & IGARCH & CGARCH \\
\hline \multicolumn{7}{|c|}{ Panel A: GARCHs augmented with oil supply shock } \\
\hline Spot VLCC & 0.955115 & 1.011391 & 0.977222 & 0.919022 & 1.043388 & 1.610478 \\
\hline Spot Suezmax & 0.954006 & 0.922193 & 0.945530 & 0.969567 & 0.944792 & 0.906079 \\
\hline Spot Aframax & 0.920701 & 0.878396 & 0.935007 & 0.843005 & 0.984372 & 1.025102 \\
\hline Spot Medium Range & 0.805422 & 0.816995 & 0.809367 & 0.823233 & 0.826320 & 0.925930 \\
\hline 1 yr TC VLCC & 0.690091 & 0.392412 & 0.704784 & 0.343276 & 0.960828 & NA \\
\hline 1 yr TC Suezmax & 0.920056 & 0.859489 & 0.673964 & 0.311722 & 0.868027 & 0.457631 \\
\hline 1 yr TC Aframax & 0.392974 & 0.517206 & 0.406448 & 0.380722 & 0.326748 & 0.812210 \\
\hline 1 yr TC Medium Range & 0.353832 & 0.613632 & 0.337857 & 0.437234 & 0.960851 & 0.880628 \\
\hline \multicolumn{7}{|c|}{ Panel B: GARCHs augmented with aggregate oil demand shock. } \\
\hline Spot VLCC & 0.950066 & 1.008583 & 0.951838 & 0.921057 & 1.080336 & 1.317928 \\
\hline Spot Suezmax & 0.945801 & 1.507488 & 0.940263 & 0.966172 & 0.959186 & 0.898175 \\
\hline Spot Aframax & 0.894251 & 0.802135 & 0.903211 & 0.846181 & 0.954141 & 1.858506 \\
\hline Spot Medium Range & 0.799931 & 0.853611 & 0.788968 & 0.857812 & 0.826998 & 1.756663 \\
\hline 1 yr TC VLCC & 0.698485 & 0.488425 & 0.712476 & 0.363880 & 0.965464 & 0.932819 \\
\hline 1 yr TC Suezmax & 0.231966 & 0.289808 & 0.709195 & 0.324477 & 0.859952 & 0.492459 \\
\hline 1 yr TC Aframax & 0.269712 & 0.533460 & 0.406654 & 0.377219 & 0.348418 & 0.808621 \\
\hline 1 yr TC Medium Range & 0.387863 & 0.661085 & 0.389125 & 0.408758 & 0.960841 & 0.824119 \\
\hline \multicolumn{7}{|c|}{ Panel C: GARCHs augmented with precautionary oil-specific demand shock. } \\
\hline Spot VLCC & 0.952137 & 0.919582 & 0.943917 & 0.883990 & 1.020891 & 0.914458 \\
\hline Spot Suezmax & 0.919424 & 0.893590 & 0.876602 & 0.927629 & 0.947991 & 1.470170 \\
\hline Spot Aframax & 0.897094 & 0.780118 & 0.905298 & 0.794884 & 0.903470 & 3.000349 \\
\hline Spot Medium Range & 0.802785 & 0.819350 & 0.799237 & 0.863526 & 0.845116 & 2.311884 \\
\hline 1 yr TC VLCC & 0.689589 & 0.390655 & 0.718911 & 0.463328 & 0.962795 & 0.878147 \\
\hline 1 yr TC Suezmax & 0.234877 & 0.225120 & 0.843313 & 0.328284 & 0.837983 & 0.476180 \\
\hline 1 yr TC Aframax & 0.267988 & 0.581318 & 0.385363 & 0.385565 & 0.329476 & 0.925297 \\
\hline 1 yr TC Medium Range & 0.355043 & 0.616243 & 0.288081 & 0.455811 & 0.965366 & 0.827281 \\
\hline
\end{tabular}

Note: Entries of Table A1 report the ratio of the RMSE metric for the GARCH-X models over the the benchmark GARCH model. The sample period spans January 1990 to December 2016. Volatility forecasts have been calculated recursively with a step of one month during the period January 2004 to December 2016. "NA" denotes that the GARCH model has not converged. 
Table A2: Forecast evaluation of the benchmark models for the tanker freight rates volatility.

\begin{tabular}{|c|c|c|c|c|c|c|}
\hline & \multicolumn{6}{|c|}{ MAE } \\
\hline & GARCH & EGARCH & TGARCH & APARCH & IGARCH & CGARCH \\
\hline Spot VLCC & 0.040509 & 0.042888 & 0.040176 & 0.040153 & 0.032758 & 0.041788 \\
\hline Spot Suezmax & 0.046755 & 0.046502 & 0.044006 & 0.043259 & 0.042720 & 0.045417 \\
\hline Spot Aframax & 0.042617 & 0.048212 & 0.042577 & 0.045732 & 0.041125 & 0.035012 \\
\hline Spot Medium Range & 0.015547 & 0.013741 & 0.013442 & 0.012567 & 0.013154 & 0.014453 \\
\hline 1 yr TC VLCC & 0.002474 & 0.004121 & 0.002601 & 0.004967 & 0.001750 & 0.001942 \\
\hline 1 yr TC Suezmax & 0.004537 & 0.002098 & 0.001810 & 0.001734 & 0.001120 & 0.003727 \\
\hline 1 yr TC Aframax & 0.002490 & 0.002422 & 0.002131 & 0.001998 & 0.000978 & 0.002894 \\
\hline \multirow[t]{3}{*}{1 yr TC Medium Range } & 0.002058 & 0.001180 & 0.002110 & 0.001066 & 0.000503 & 0.000628 \\
\hline & \multicolumn{6}{|c|}{ MSE } \\
\hline & GARCH & EGARCH & TGARCH & APARCH & IGARCH & CGARCH \\
\hline Spot VLCC & 0.003024 & 0.003126 & 0.002998 & 0.003269 & 0.002480 & 0.003024 \\
\hline Spot Suezmax & 0.004120 & 0.004162 & 0.004097 & 0.004045 & 0.003924 & 0.004195 \\
\hline Spot Aframax & 0.003694 & 0.004490 & 0.003535 & 0.004180 & 0.003208 & 0.002945 \\
\hline Spot Medium Range & 0.000428 & 0.000364 & 0.000412 & 0.000350 & 0.000373 & 0.000410 \\
\hline $1 \mathrm{yr}$ TC VLCC & $1.63 \mathrm{E}-05$ & $7.35 \mathrm{E}-05$ & $1.56 \mathrm{E}-05$ & $7.51 \mathrm{E}-05$ & $8.47 \mathrm{E}-06$ & $9.87 \mathrm{E}-06$ \\
\hline 1 yr TC Suezmax & $8.18 \mathrm{E}-05$ & 0.000112 & $1.01 \mathrm{E}-05$ & $4.87 \mathrm{E}-05$ & 6.00E-06 & $2.57 \mathrm{E}-05$ \\
\hline 1 yr TC Aframax & $2.97 \mathrm{E}-05$ & $1.66 \mathrm{E}-05$ & $3.33 \mathrm{E}-05$ & $1.80 \mathrm{E}-05$ & $1.28 \mathrm{E}-05$ & $1.43 \mathrm{E}-05$ \\
\hline \multirow[t]{3}{*}{1 yr TC Medium Range } & $1.29 \mathrm{E}-05$ & $4.38 \mathrm{E}-06$ & $1.91 \mathrm{E}-05$ & $9.87 \mathrm{E}-06$ & $1.23 \mathrm{E}-06$ & $1.70 \mathrm{E}-06$ \\
\hline & \multicolumn{6}{|c|}{ RMSE } \\
\hline & GARCH & EGARCH & TGARCH & APARCH & IGARCH & $\mathrm{CGARCH}$ \\
\hline Spot VLCC & 0.054990 & 0.053929 & 0.054758 & 0.057176 & 0.049800 & 0.054989 \\
\hline Spot Suezmax & 0.064191 & 0.064511 & 0.064011 & 0.063599 & 0.062640 & 0.064769 \\
\hline Spot Aframax & 0.060781 & 0.067008 & 0.059456 & 0.064652 & 0.056636 & 0.054267 \\
\hline Spot Medium Range & 0.020699 & 0.019081 & 0.020304 & 0.018717 & 0.019310 & 0.020242 \\
\hline 1 yr TC VLCC & 0.004039 & 0.008575 & 0.003944 & 0.008667 & 0.002911 & 0.003141 \\
\hline 1 yr TC Suezmax & 0.009047 & 0.010600 & 0.003183 & 0.006982 & 0.002449 & 0.005074 \\
\hline 1 yr TC Aframax & 0.005450 & 0.004078 & 0.005770 & 0.004240 & 0.003576 & 0.003775 \\
\hline 1 yr TC Medium Range & 0.003597 & 0.002092 & 0.004371 & 0.003142 & 0.001107 & 0.001306 \\
\hline
\end{tabular}

Note: Table A2 reports the mean absolute error (MAE), mean squared error (MSE) and root mean squared error (RMSE) for the benchmark GARCH models. The sample period runs from January 1990 to December 2016. The tanker freight rates volatility forecasts have been obtained recursively for the period January 2004 to December 2016. Bold fonts indicate the lowest forecast error across the models. 
Table A3: Forecast evaluation of the GARCH-X model including oil supply shock based on the MAE, MSE and RMSE.

\begin{tabular}{|c|c|c|c|c|c|c|}
\hline \multicolumn{7}{|c|}{ MAE } \\
\hline & GARCH & EGARCH & TGARCH & APARCH & IGARCH & $\mathrm{CGARCH}$ \\
\hline Spot VLCC & 0.031506 & 0.036350 & 0.033720 & 0.035884 & 0.036913 & 0.070432 \\
\hline Spot Suezmax & 0.040788 & 0.031569 & 0.038886 & 0.033858 & 0.037665 & 0.038987 \\
\hline Spot Aframax & 0.034938 & 0.033347 & 0.033288 & 0.030269 & 0.035990 & 0.035828 \\
\hline Spot Medium Range & 0.008991 & 0.008064 & 0.008869 & 0.007966 & 0.009079 & 0.013460 \\
\hline 1 yr TC VLCC & 0.001585 & 0.001765 & 0.001621 & 0.001696 & 0.001636 & NA \\
\hline 1 yr TC Suezmax & 0.001708 & 0.001765 & 0.001073 & 0.000973 & 0.000999 & 0.001075 \\
\hline 1 yr TC Aframax & 0.001119 & 0.000860 & 0.001099 & 0.000862 & 0.000677 & 0.000835 \\
\hline 1 yr TC Medium Range & 0.000670 & 0.000707 & 0.000941 & 0.000790 & 0.000475 & 0.000516 \\
\hline \multicolumn{7}{|c|}{ MSE } \\
\hline & GARCH & EGARCH & TGARCH & APARCH & IGARCH & $\mathrm{CGARCH}$ \\
\hline Spot VLCC & 0.002759 & 0.002975 & 0.002863 & 0.002761 & 0.002700 & 0.007843 \\
\hline Spot Suezmax & 0.003750 & 0.003539 & 0.003663 & 0.003802 & 0.003502 & 0.003444 \\
\hline Spot Aframax & 0.003132 & 0.003464 & 0.003090 & 0.002970 & 0.003108 & 0.003095 \\
\hline Spot Medium Range & 0.000278 & 0.000243 & 0.000270 & 0.000237 & 0.000255 & 0.000351 \\
\hline 1 yr TC VLCC & 7.77E-06 & $1.13 \mathrm{E}-05$ & 7.73E-06 & 8.85E-06 & $7.82 \mathrm{E}-06$ & NA \\
\hline 1 yr TC Suezmax & $6.93 \mathrm{E}-05$ & $8.30 \mathrm{E}-05$ & 4.60E-06 & 4.74E-06 & $4.52 \mathrm{E}-06$ & $5.39 \mathrm{E}-06$ \\
\hline 1 yr TC Aframax & $4.59 \mathrm{E}-06$ & $4.45 \mathrm{E}-06$ & $5.50 \mathrm{E}-06$ & $2.61 \mathrm{E}-06$ & $1.37 \mathrm{E}-06$ & $9.40 \mathrm{E}-06$ \\
\hline 1 yr TC Medium Range & $1.62 \mathrm{E}-06$ & $1.65 \mathrm{E}-06$ & $2.18 \mathrm{E}-06$ & $1.89 \mathrm{E}-06$ & $1.13 \mathrm{E}-06$ & $1.32 \mathrm{E}-06$ \\
\hline \multicolumn{7}{|c|}{ RMSE } \\
\hline & GARCH & EGARCH & TGARCH & APARCH & IGARCH & $\mathrm{CGARCH}$ \\
\hline Spot VLCC & 0.052522 & 0.054543 & 0.053511 & 0.052546 & 0.051960 & 0.088559 \\
\hline Spot Suezmax & 0.061239 & 0.059491 & 0.060524 & 0.061663 & 0.059181 & 0.058686 \\
\hline Spot Aframax & 0.055961 & 0.058859 & 0.055592 & 0.054502 & 0.055751 & 0.055629 \\
\hline Spot Medium Range & 0.016671 & 0.015589 & 0.016433 & 0.015408 & 0.015956 & 0.018743 \\
\hline 1 yr TC VLCC & 0.002787 & 0.003365 & 0.002780 & 0.002975 & 0.002797 & NA \\
\hline 1 yr TC Suezmax & 0.008324 & 0.009111 & 0.002145 & 0.002176 & 0.002126 & 0.002322 \\
\hline 1 yr TC Aframax & 0.002142 & 0.002109 & 0.002345 & 0.001614 & 0.001168 & 0.003066 \\
\hline 1 yr TC Medium Range & 0.001273 & 0.001284 & 0.001477 & 0.001374 & 0.001064 & 0.001150 \\
\hline
\end{tabular}

Note: Table A3 reports the mean absolute error (MAE), mean squared error (MSE) and root mean squared error (RMSE) for the GARCH-X model including oil supply shock. The sample period spans January 1990 to December 2016. Volatility forecasts have been calculated recursively with a step of one month during the period January 2004 to December 2016. Bold fonts indicate the lowest forecast error across different GARCH specifications for each freight rate series examined. 
Table A4: Forecast evaluation of the GARCH-X model including aggregate demand shock based on the MAE, MSE and RMSE.

\begin{tabular}{|c|c|c|c|c|c|c|}
\hline \multicolumn{7}{|c|}{ MAE } \\
\hline & GARCH & EGARCH & TGARCH & APARCH & IGARCH & CGARCH \\
\hline Spot VLCC & 0.031896 & 0.035678 & 0.032403 & 0.036086 & 0.036223 & 0.054599 \\
\hline Spot Suezmax & 0.037292 & 0.039688 & 0.035554 & 0.033917 & 0.038219 & 0.037254 \\
\hline Spot Aframax & 0.033561 & 0.029572 & 0.033727 & 0.031404 & 0.034206 & 0.074994 \\
\hline Spot Medium Range & 0.009184 & 0.008398 & 0.008709 & 0.008280 & 0.009382 & 0.027161 \\
\hline 1 yr TC VLCC & 0.001592 & 0.001893 & 0.001639 & 0.001880 & 0.001632 & 0.001666 \\
\hline 1 yr TC Suezmax & 0.001038 & 0.001207 & 0.001161 & 0.001027 & 0.001018 & 0.001379 \\
\hline 1 yr TC Aframax & 0.000811 & 0.000915 & 0.001175 & 0.000843 & 0.000658 & 0.001017 \\
\hline 1 yr TC Medium Range & 0.000703 & 0.000601 & 0.000828 & 0.000590 & 0.000475 & 0.000457 \\
\hline \multicolumn{7}{|c|}{ MSE } \\
\hline & GARCH & EGARCH & TGARCH & APARCH & IGARCH & CGARCH \\
\hline Spot VLCC & 0.002729 & 0.002958 & 0.002717 & 0.002773 & 0.002894 & 0.005252 \\
\hline Spot Suezmax & 0.003686 & 0.009457 & 0.003622 & 0.003776 & 0.003610 & 0.003384 \\
\hline Spot Aframax & 0.002954 & 0.002889 & 0.002884 & 0.002993 & 0.002920 & 0.010172 \\
\hline Spot Medium Range & 0.000274 & 0.000265 & 0.000257 & 0.000258 & 0.000255 & 0.001264 \\
\hline 1 yr TC VLCC & $7.96 \mathrm{E}-06$ & $1.75 \mathrm{E}-05$ & $7.90 \mathrm{E}-06$ & $9.95 \mathrm{E}-06$ & $7.89 \mathrm{E}-06$ & $8.59 \mathrm{E}-06$ \\
\hline 1 yr TC Suezmax & $4.40 \mathrm{E}-06$ & $9.44 \mathrm{E}-06$ & $5.09 \mathrm{E}-06$ & $5.13 \mathrm{E}-06$ & $4.43 \mathrm{E}-06$ & $6.24 \mathrm{E}-06$ \\
\hline 1 yr TC Aframax & $2.16 \mathrm{E}-06$ & $4.73 \mathrm{E}-06$ & $5.51 \mathrm{E}-06$ & $2.56 \mathrm{E}-06$ & $1.55 \mathrm{E}-06$ & $9.32 \mathrm{E}-06$ \\
\hline 1 yr TC Medium Range & $1.95 \mathrm{E}-06$ & $1.91 \mathrm{E}-06$ & $2.89 \mathrm{E}-06$ & $1.65 \mathrm{E}-06$ & $1.13 \mathrm{E}-06$ & $1.16 \mathrm{E}-06$ \\
\hline \multicolumn{7}{|c|}{ RMSE } \\
\hline & GARCH & EGARCH & TGARCH & APARCH & IGARCH & CGARCH \\
\hline Spot VLCC & 0.052245 & 0.054392 & 0.052121 & 0.052662 & 0.053800 & 0.072472 \\
\hline Spot Suezmax & 0.060712 & 0.097249 & 0.060187 & 0.061448 & 0.060083 & 0.058174 \\
\hline Spot Aframax & 0.054353 & 0.053749 & 0.053701 & 0.054707 & 0.054039 & 0.100856 \\
\hline Spot Medium Range & 0.016558 & 0.016288 & 0.016019 & 0.016056 & 0.015969 & 0.035559 \\
\hline 1 yr TC VLCC & 0.002821 & 0.004188 & 0.002815 & 0.003154 & 0.002810 & 0.002930 \\
\hline 1 yr TC Suezmax & 0.002099 & 0.003072 & 0.002257 & 0.002266 & 0.002106 & 0.002499 \\
\hline 1 yr TC Aframax & 0.001470 & 0.002175 & 0.002346 & 0.001599 & 0.001246 & 0.003053 \\
\hline 1 yr TC Medium Range & 0.001395 & 0.001383 & 0.001701 & 0.001284 & 0.001064 & 0.001076 \\
\hline
\end{tabular}

Note: Table A4 reports the mean absolute error (MAE), mean squared error (MSE) and root mean squared error (RMSE) for the GARCH-X model including aggregate demand shock. The sample period spans January 1990 to December 2016. Volatility forecasts have been calculated recursively with a step of one month during the period January 2004 to December 2016. Bold fonts indicate the lowest forecast error across different GARCH specifications for each freight rate series examined. 
Table A5: Forecast evaluation of the GARCH-X model including oil-specific (precautionary) demand shock based on the MAE, MSE and RMSE.

\begin{tabular}{|c|c|c|c|c|c|c|}
\hline \multicolumn{7}{|c|}{ MAE } \\
\hline & GARCH & EGARCH & TGARCH & APARCH & IGARCH & CGARCH \\
\hline Spot VLCC & 0.032190 & 0.030693 & 0.032136 & 0.031921 & 0.033085 & 0.032920 \\
\hline Spot Suezmax & 0.037382 & 0.035151 & 0.035768 & 0.036156 & 0.037293 & 0.074984 \\
\hline Spot Aframax & 0.034109 & 0.028320 & 0.034548 & 0.028478 & 0.032423 & 0.086527 \\
\hline Spot Medium Range & 0.009253 & 0.008091 & 0.008912 & 0.008381 & 0.009643 & 0.041548 \\
\hline 1 yr TC VLCC & 0.001629 & 0.001685 & 0.001669 & 0.002594 & 0.001595 & 0.001619 \\
\hline 1 yr TC Suezmax & 0.001037 & 0.001171 & 0.001263 & 0.001048 & 0.001051 & 0.001174 \\
\hline 1 yr TC Aframax & 0.000839 & 0.001099 & 0.001164 & 0.000938 & 0.000638 & 0.001102 \\
\hline 1 yr TC Medium Range & 0.000643 & 0.000619 & 0.000887 & 0.000735 & 0.000483 & 0.000468 \\
\hline \multicolumn{7}{|c|}{ MSE } \\
\hline & GARCH & EGARCH & TGARCH & APARCH & IGARCH & CGARCH \\
\hline Spot VLCC & 0.002741 & 0.002459 & 0.002672 & 0.002555 & 0.002585 & 0.002529 \\
\hline Spot Suezmax & 0.003483 & 0.003323 & 0.003149 & 0.003481 & 0.003526 & 0.009067 \\
\hline Spot Aframax & 0.002973 & 0.002733 & 0.002897 & 0.002641 & 0.002618 & 0.026511 \\
\hline Spot Medium Range & 0.000276 & 0.000244 & 0.000263 & 0.000261 & 0.000266 & 0.002190 \\
\hline 1 yr TC VLCC & 7.76E-06 & $1.12 \mathrm{E}-05$ & 8.04E-06 & $1.61 \mathrm{E}-05$ & 7.85E-06 & 7.61E-06 \\
\hline 1 yr TC Suezmax & 4.52E-06 & $5.69 \mathrm{E}-06$ & $7.20 \mathrm{E}-06$ & $5.25 \mathrm{E}-06$ & $4.21 \mathrm{E}-06$ & $5.84 \mathrm{E}-06$ \\
\hline 1 yr TC Aframax & $2.13 \mathrm{E}-06$ & $5.62 \mathrm{E}-06$ & $4.94 \mathrm{E}-06$ & $2.67 \mathrm{E}-06$ & 1.39E-06 & $1.22 \mathrm{E}-05$ \\
\hline 1 yr TC Medium Range & 1.63E-06 & $1.66 \mathrm{E}-06$ & $1.59 \mathrm{E}-06$ & $2.05 \mathrm{E}-06$ & $1.14 \mathrm{E}-06$ & $1.17 \mathrm{E}-06$ \\
\hline \multicolumn{7}{|c|}{ RMSE } \\
\hline & GARCH & EGARCH & TGARCH & APARCH & IGARCH & CGARCH \\
\hline Spot VLCC & 0.052358 & 0.049592 & 0.051687 & 0.050543 & 0.050840 & 0.050285 \\
\hline Spot Suezmax & 0.059019 & 0.057646 & 0.056112 & 0.058996 & 0.059382 & 0.095221 \\
\hline Spot Aframax & 0.054526 & 0.052274 & 0.053826 & 0.051391 & 0.051169 & 0.162821 \\
\hline Spot Medium Range & 0.016617 & 0.015634 & 0.016228 & 0.016162 & 0.016319 & 0.046798 \\
\hline 1 yr TC VLCC & 0.002785 & 0.003350 & 0.002835 & 0.004016 & 0.002802 & 0.002759 \\
\hline 1 yr TC Suezmax & 0.002125 & 0.002386 & 0.002684 & 0.002292 & 0.002052 & 0.002416 \\
\hline 1 yr TC Aframax & 0.001460 & 0.002371 & 0.002223 & 0.001635 & 0.001178 & 0.003493 \\
\hline 1 yr TC Medium Range & 0.001277 & 0.001289 & 0.001259 & 0.001432 & 0.001069 & 0.001080 \\
\hline
\end{tabular}

Note: Table A5 reports the mean absolute error (MAE), mean squared error (MSE) and root mean squared error (RMSE) for the GARCH-X model including oil-specific (precautionary) demand shock. The sample period spans January 1990 to December 2016. Volatility forecasts have been calculated recursively with a step of one month during the period January 2004 to December 2016. Bold fonts indicate the lowest forecast error across different GARCH specifications for each freight rate series examined. 